\title{
Cidade e Políticas Sociais de Habitação Armadilhas Conceptuais e Metodológicas ${ }^{1}$
}

Luís Vicente Baptista*

\begin{abstract}
$\mathrm{R}$ social torna-a alvo dos mais variados equacionamentos, perspectivas e iniciativas. Concretamente, a intervenção pública neste campo específico levou a que se viesse a desenvolver uma área de actividades(s), particularmente importante no interior e na extensão envolvente das nossas cidades, que podemos designar por Habitação Social.

Neste artigo procuramos levantar a discussão acerca das armadilhas analíticas que resultam da forma como os discursos - político, técnico e científico - e as várias práticas e valências profissionais envolvidas na definição da melhor forma de intervenção do Estado no campo da habitação reflectem e dão expressão ao conflito de interesses dos grupos profissionais, políticos, sociais e económicos.

Tentamos em dois tempos apresentar exemplos daquilo que aqui designamos por armadilhas conceptuais e de armadilhas metodológicas. Procuramos identificar as dificuldades que o sociólogo que investiga nestes domínios encontra ao lidar com as pré-noções resultantes da intensa vivência que este problema (social da habitação) implica. Sem qualquer intenção de esgotar a questão pretendemos, primeiro, através da experiência de relação com o mundo dos interventores e, seguidamente, na sequência da experiência pessoal de investigação do processo que dá origem às actuais intervenções públicas neste sector, fazer um primeiro ponto de situação desta problemática.
\end{abstract}

Palavras-chave: cidade; políticas sociais; habitação; armadilhas conceptuais e metodológicas.

\section{Introdução}

A cidade, enquanto objecto de análise, visivelmente dinâmico, constitui o lugar polifacetado da coexistência de populações e de modos de vida. Mas a sua realidade, apesar de delineável espacialmente, interessa ao sociólogo sobretudo enquanto observatório privilegiado a partir do qual se pode perspectivar sintomaticamente as várias dimensões da mudança nas sociedades contemporâneas. E isto porque os fenómenos tomam aí as colorações mais intensas, o que resulta da proeminência dos interesses em presença, permitindo a mais fácil identificação de novas modalidades de relação social.

Ora, precisamente, um dos domínios de análise mais fascinantes para acompanhar estas transformações de que vai sendo alvo a cidade é o da reinvenção morfológica, o que implica o engenho de trazer à superfície edificada e vivida da cidade a expressão dos interesses particulares e colectivos dos interventores urbanos. Pretende- se chegar à caracterização dos modos de edificação e de recomposição populacional da

\footnotetext{
* Sociólogo, Prof. Auxiliar no Departamento de Sociologia da FCSH/UNL.

1 Este artigo sintetiza algumas preocupações que desenvolvemos em trabalhos anteriores. Remetemos a maior extensão das referências bibliográficas para o trabalho Cidade em Reinvenção. Crescimento L'rbano e Emer ência das Políticas Sociais de Habitação. Lisboa, século vinte, Dissertação de Doutoramento em Sociologia, FCSH-UNL, 1996. Uma primeira versão deste texto foi apresentada oralmente no IV Congresso da APS que decorreu em Coimbra em Abril de 2000.
} 
cidade actual e por esta via perscrutar as modalidades de acção que se associam à experiência da urbe.

Esta perspectiva necessita para ganhar dimensão explicativa de ser processual: é essencial recuar historicamente de modo a poder compreender as dinâmicas sociopolíticas e demográficas próprias da cidade que é hoje o nosso cenário quotidiano.

A imagem que nos ocorre, embora extremada, é clarificadora. A cidade actual, resultado cumulativo das cidades que a partir do núcleo inicial se vão estendendo progressivamente para fora das "muralhas" e que nos vários momentos vão separando os citadinos dos outros, é circunstancial. Circunstancial porque é apenas a "cidade do momento" permeável à mudança que fará dela uma outra cidade. Assim, a "cidade do momento" é mobilizável para os novos momentos históricos graças à sua plasticidade que se confirma quer na actualização da sua estrutura física quer na redefinição das relações sociais protagonizadas por velhos e por emergentes grupos sociais e profissionais.

Objecto mutante, a cidade actual é espaço aberto de disputas e conflitos mas também de experiências de partilha e troca. O campo da habitação, por exemplo, é disso bem indicativo. Revela-se recheado das contradições inerentes à variedade de pontos de vista dos protagonistas que (em enorme número) aí intervêm, desde os seus decisores, aos seus edificadores, aos seus utilizadores.

Ora, esta proliferação de participantes obriga-nos a acentuar a vigilância na observação do fenómeno e a cuidar mais intensamente da relativização dos pontos de vista em presença. Desde logo nos deparamos com um primeiro nível de compreensão em que os agentes estabelecem acerca da realidade perspectivas próprias, egocentradas e autoreferenciais. Obviamente estamos no plano das avaliações pessoais, impressionistas, onde imperam visões vincadas pelas concepções de senso comum e nas quais se albergam os pontos de vista ideológicos quer face à cidade quer face à problemática habitacional.

Estas percepções são alimentadas pelas pré-noções socialmente congeminadas no quadro da socialização urbana ${ }^{2}$ e têm um papel central no sentido de fazerem com que a linha de conduta seguida por cada agente social se vá delineando em conformidade com pressupostos gerais de acção socialmente partilhados. As ideologias urbanas ${ }^{3}$, verbalizadas e usadas por diferentes grupos de protagonistas como arma de arremesso político, veêm-se reforçadas e reforçam as convicções dos que nelas se revêem. As convicções, aparentemente individuais, acerca de como deveria ser a cidade ou de com quem se deveria conviver na cidade revelam cosmovisões que ganham sintonia e produzem identificações, acabando por classificar os outros, os seus lugares e as suas práticas sociais.

É aliás significativo que as propriedades sociais associadas a um lugar tresvasem para as populações que o habitam ${ }^{4}$. Todavia, a cidade, feita de diversidade e de dinamismo, comporta ritmos de transformação, que permitem reconfigurações de tal forma radicais e rápidas que a coloração social ${ }^{5}$ associada a um certo local tende a ser relativamente fluida podendo mesmo ser alterada com alguma facilidade. Os exemplos de situações que obrigam ao convívio temporário, por exemplo, entre velhos habitantes de bairros tradicionais com novos utentes de serviços especifícos das grandes cidades (sobretudo nas áreas centrais da cidade) ou de grupos sociais e etários em momentos diversos das suas carreiras residenciais (sobretudo no âmbito de grandes conjuntos habitacionais de iniciativa pública) são frequentes. Também a requalificação das "frentes de água" aponta no sentido dessa reconversão social do espaço urbano. Lisboa propriamente dita viveu na experiência da Expo'98, actualmente Parque das Nações, a sua creditação enquanto cidade mutante ${ }^{6}$.

\footnotetext{
${ }^{2}$ Esta noção de socialização urbana remete para uma forma de socialização secundária, desenvolvida analiticamente por Guy Barbichon (ver Bibliografia). No nosso caso ampliamos esta dimensão numa perspectiva menos exclusiva da situação de emigração campo-cidade mas antes de posicionamento face à vida urbana que percorre todo o processo de socialização, independentemente do(s) contextos socio-ecológico(s) de socialização.

${ }^{3}$ Para melhor esclarecimento deste conceito consultar a obra de Raymond Ledrut (ver Bibliografia).

${ }^{4}$ Por exemplo, a catalogação dos sítios destinados ao realojamento como indesejáveis é bem frequente. Desde logo a desvalorização social dos lugares envolventes promove o afastamento de outras populações das vizinhanças que não se querem identificar com a condição de «realojado» e que reclamam face à ainda hipotética desvalorização económica dos terrenos e edifícios de que são proprietários ou usufrutuários.

${ }^{5}$ Remetemos esta questão da tonalidade social de um bairro para o trabalho clássico de Jean-Claude Chamboredon e Madelaine Lemaire (ver Bibliografia).

${ }^{6}$ Em jeito de síntese consultar os trabalhos que Vítor Matias Ferreira e a sua equipa vêm divulgando sobre este tema e o número temático da
} revista Mediterrâneo "Cidades, Portos e Frentes de Água” (ver Bibliografia). 


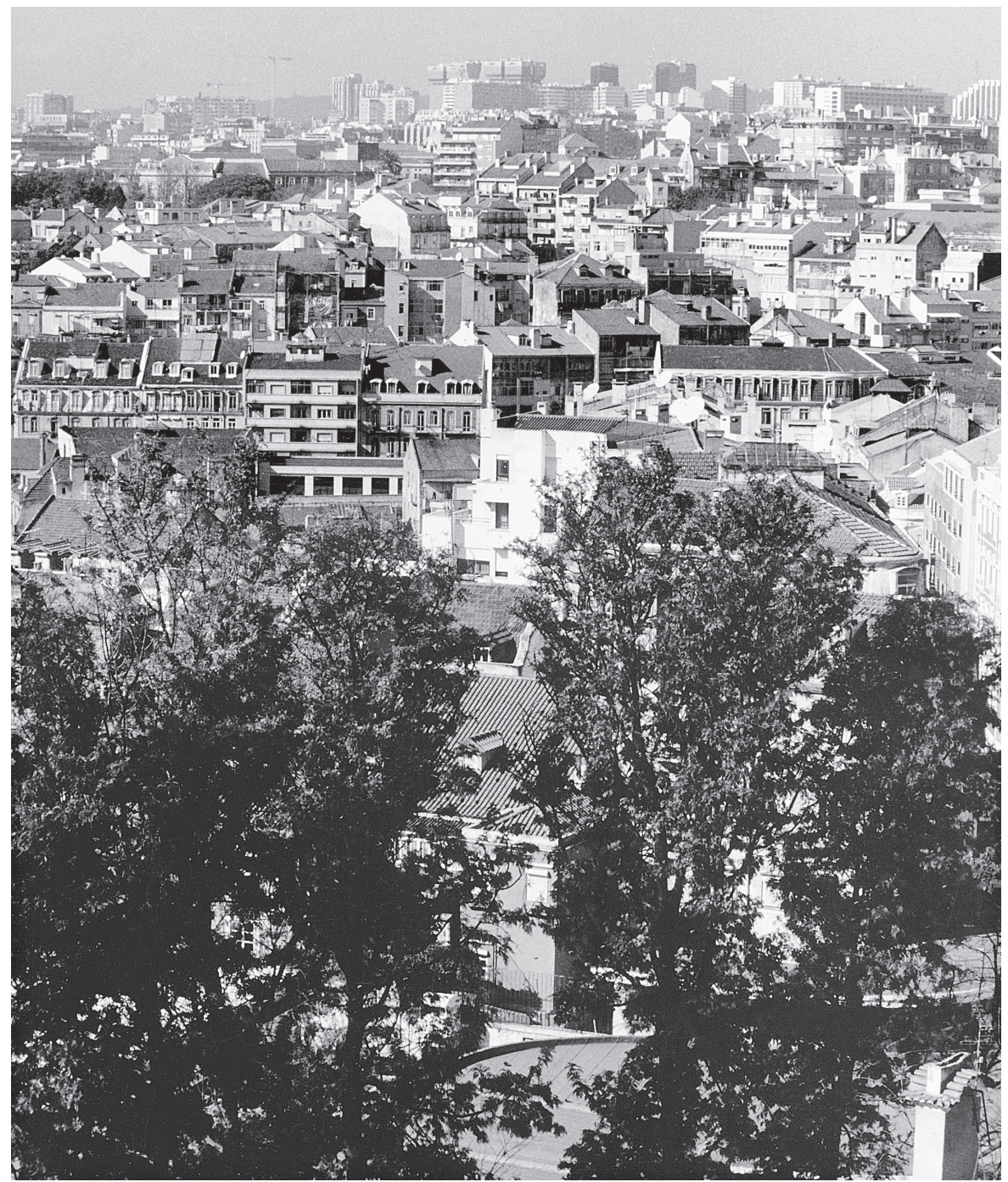

Foto de Miguel Baltazar

\section{Armadilhas Conceptuais na Análise das Relações entre Cidade, Políticas Sociais e Habitação}

Se o trabalho do investigador que lida com a cidade está dificultado pelo carácter polifacetado da coexistência de populações e de modos de vida, então, a pesquisa da questão habitacional revela-se particularmente difícil já que este é um domínio analítico no qual se cruzam a polifonia dos interesses dos residentes, ou seja, de todos. Deste modo não há como evitar o efeito de contaminação entre a nossa experiência quotidiana e os discursos acerca da realidade, sejam eles proclamados por agentes sociais implicados na questão ou por agentes técnicos e científicos. Há pois que reflectir acerca do ponto de vista dos observadores e dos participantes, analisando os discursos proferidos (inflamados e inflacionados) e as práticas efectivas.
Preventivamente há desde logo que antecipar um certo tipo de procedimento metodológico e conceptual. Tal preocupação implica identificar os bloqueios que são recorrentes dentro de uma postura reificadora na análise das questões sociais e à qual também os sociólogos não são alheios. Implica igualmente combater a indefinição dos termos usados e dos pontos de vista tomados, evitando assim efeitos devastadores na clarificação tanto do próprio objecto em estudo como no objectivo de obter resultados de pesquisa com pertinência sociológica.

\section{A Habitação como Problema Social e como Problema Sociológico}

Em primeiro lugar há que assinalar o desfasamento evidente entre o entendimento da Habitação como um relevante problema social e enquanto problema sociolológico. 
Se entendermos a Habitação nesta sua primeira dimensão, de problema social, poderemos sem esforço identificar de forma clara um campo social de interesse. Em seu torno se posicionam todo um conjunto de interventores públicos e privados que no seu âmbito fazem a gestão dos seus interesses e competem no sentido de melhor se localizarem, reforçando o seu poder relativo. A relevância da questão habitacional comporta várias subdivisões das quais a mais sujeita à visibilidade dos mass media parece ser a da habitação de iniciativa ou com participação pública (normalmente designada como habitação social). E isto por duas razões. Uma, porque estamos a lidar com populações que vivem no limiar da insolvência económica e de uma perfilada exclusão social. Há pois aqui um óbvio palco de discussão aberto em volta da temática da cidadania, resultante do pressuposto próprio das sociedades democráticas contemporâneas da necessidade de garantir os direitos sociais. Outra, porque o envolvimento de verbas públicas em iniciativas urbanísticas e habitacionais nem sempre é evidente quanto ao seu valor social, suscitando a sua concretização particular curiosidade quer no plano do combate político quer no da disputa técnica (na busca da melhor solução).

Já o entendimento da habitação como problema sociológico merece outra atenção. Será antes de tudo necessário distinguir dois tipos de trabalho ambos de teor sociológico.

Por um lado, temos o trabalho sociológico de análise dos processos de crescimento urbano, de alteração dos habitats urbanos tradicionais e de reconversão da relações de sociabilidade em contextos de crescente mobilidade geográfica e social. Neste plano a questão da habitação, embora sempre presente, não ocupa qualquer outro protagonismo que não seja o de percorrer todos os domínios da vida social como elemento agregador fundamental das relações sociais. Sendo um tipo de pesquisa realizada de forma distanciada das pressões de ordem social e política, tem o seu epicentro analítico na velha questão urbana e nas preocupações teóricas que lhe estão associadas.

Por outro lado, temos o trabalho dos sociólogos envolvidos nos processos de intervenção nos quais os seus recursos técnicos-científicos são recrutados no âmbito de uma experimentação urbanística e habitacional. Neste âmbito, todo o acervo de conhecimentos desenvolvidos contribui para a autonomização parcial do conhecimento por definição interdisciplinar em torno do objecto habitação. Também por via da componente sociológica, a Habitação ganha aqui o protago- nismo que a anterior visão não lhe confere. Ora, a inegável importância que tem o objecto-Habitação encontra nesta perspectiva a sua plena consubstanciação dada a premência de encontrar respostas cientificamente controladas às questões socialmente colocadas. A este nível, as imposições e as reivindicações de vária ordem a que os interventores públicos estão sujeitos vai estabelecer uma espécie de fosso entre a visão dos que no terreno trabalham sob a pressão da opinião pública e dos objectivos da própria intervenção, orientados para fins práticos (da resolução de problemas concretos), e a dos que reflectem distanciados deste trabalho de concepção, programação e execução das iniciativas de ordenamento do espaço residencial.

Isto faz do trabalho do sociólogo de terreno uma tarefa particularmente espinhosa. E se já a propósito do repositório de enfoques que se projectam acerca da questão da habitação, Isabel Guerra nos alerta precisamente para a diversidade das suas orientações, e mesmo para a sectorialização que as questões do alojamento vão tomando segundo as perspectivas que emanam do campo de produção sociológico, concretamente acerca da difícil articulação dos sociólogos em equipas multidisciplinares a autora avança uma explicação absolutamente clarificadora: "De facto, as pesquisas e os projectos de intervenção-acção vieram demonstrar as dificuldades das ciências sociais em clarificar a relação entre a arquitectura e o espaço (i.e., entre o comportamento e as formas espaciais). Se o saber dos sociólogos sobre os modos de vida e o habitat não se impôs como um adquirido, é porque a sociologia trabalha com realidades complexas, de causalidades não lineares e sempre em mudança. Perante o trabalho multidisciplinar, poucos sociólogos de terreno parecem conseguir lidar satisfatoriamente com o stress que advém da relação complexa entre a análise de uma realidade multifacetada e dispersa, e a necessidade de dar respostas operacionais. Simultaneamente, é difícil não cair numa análise linear e simplista, mantendo um estatuto profissional e paritário com outras profissões ditas "mais operacionais" (Guerra,1997:172).

\section{O Problema da Habitação, os Campos Científicos e os Campos de Aplicação de Conhecimentos}

A polémica é acesa e permanente. É simultaneamente interdisciplinar e intradisciplinar, percorrendo tanto os campos de produção de 
conhecimentos científicos como os domínios de aplicação mais ou menos autónomos que daí resultam. Há pois em primeiro lugar que distinguir entre os campos científicos como a Sociologia, as outras Ciências Sociais, as Engenharias, a Arquitectura e os campos de aplicação de conhecimento (técnico-científicos) como o Urbanismo, campo legitimador das técnicas, das práticas técnico-profissionais no âmbito das quais se discute a "boa forma", a "boa prática", a "boa solução".

E tanto no primeiro circuito, o da produção de retóricas concorrentes acerca da maneira de entender a realidade habitacional, como no segundo, da legitimação profissional das intervenções urbanísticas, as disputas quanto à melhor definição são evidentes. Veja-se, por exemplo, no plano dos modos de intervenção dos produtores do espaço edificado destinado a habitar, os desempenhos profissionais distintos de arquitectos, engenheiros, urbanistas (eles próprios divididos face a pontos de vista internos às disciplinas em que se localizam), dos outros edificadores leigos, vulgo construtores civis e, inevitavemente, dos políticos.

Se aprofundarmos a análise vamos constatar que, cumulativamente, as retóricas concorrentes tanto perpassam o confronto entre disciplinas como percorrem o nível específico de cada disciplina. No caso da Sociologia o problema parece partir do posicionamento face ao dilema "problema social/problema sociológico". E conduz frequentemente à questão da divisão (simbólica e social) do trabalho sociológico. Assim são recorrentes as imagens estereotipadas dos profissionais-sociólogos e dos sociólogos-académicos, os primeiros supostamente construtores de práticas profissionais orientadas para a participação da visão sociológica no domínio da resolução dos problemas sociais e os segundos, sediados na campo universitário, supostamente veiculadores e definidores das novas certezas institucionais do território sociológico.

Na prática, a construção destas imagens tipificadas, entre os que se afirmam profissionalmente como sociólogos, vai conduzir à discussão dos papéis sociais do sociológo e aos seus possíveis desempenhos. O papel do sociólogo-planeador, membro de equipas pluridisciplinares é um deles. Falamos aqui dos sociólogos enquanto profissionais que trabalham como interventores, técnicos legitimamente orientados para a tomada de decisões. E tal como no campo universitário, há aqui que colocar a questão da relevância do conhecimento sociológico no contexto das disciplinas envolvidas no processo interventivo.

É relativamente evidente que as preocupações sociológicas (a não confundir com preocupações sociais partilhadas com os oriundos de todo os restantes campos científicos!) têm habitualmente um lugar periférico na hierarquia dos conhecimentos valorizados no quadro de uma intervenção urbanística pelo que de forma frequente são reduzidas à escala de "uma engenharia do desenolvimento social" (retomo aqui o título de um livro de Michel Bonetti) ou a um trabalho de planeamento ou gestão urbanos.

Ora, sociólogos como Artemio Baigorri vêm discutindo o sentido da contribuição sociológica no campo do urbanismo, defendendo posições centradas na necessidade de um salto qualitativo face ao Urbanismo actual (veja-se o seu artigo "Del urbanismo multidisciplinario a la urbanítica transdisciplinaria. Una perspectiva sociológica"). Tal pretensão assenta na busca de novos paradigmas de actuação, essenciais no plano da tomada de decisões e nas relações sociais quotidianas. Todavia, o plano em que se trabalha neste campo de aplicação de conhecimento não pode deixar de ser normativo porque há que garantir a eficácia no domínio da intervenção e na resolução dos problemas sociais. E nessa medida esta perspectiva exclui a reflexão sociológica sobre os procedimentos dos agentes e as formas instituídas de relação social e profissional dos participantes no campo do Urbanismo, já que esse não é o objectivo da presença de sociólogos nestas equipas. É óbvio que tal questionamento tem melhores condições para se efectivar no campo universitário no qual o trabalho sociológico se encontra habitualmente desvinculado dos campos de intervenção social.

Nestas condições cria-se a possibilidade de exercitar o distanciamento crítico. A investigação desenvolvida por Christian Topalov na qual clarifica o processo que conduz à estabilização do plano normativo no campo do urbanismo, analisando a afirmação da ideia de "norma urbanística" (Topalov,1990:370), é disso exemplo. A esta se refere Topalov defendendo o papel central que este instrumento relativamente desideologizado tem no contexto da emergência do Urbanismo. A sua aceitação decorre do consenso que se foi concretizando politicamente no virar do secúlo XIX para o XX entre certos sectores da burguesia e sectores da elite operária que pela Europa em industrialização promovem a 
transferência do odioso da "questão operária" para o palco reformista dos "problemas sociais dos operários".

O urbanismo, que teria como cenário por excelência as cidades-metrópole, passa então a ter um papel regulador nas próprias relações entre classes, baseando-se no rigor técnico e no princípio político de uma distribuição mais equitativa de bens que não eram até então entendidos como socialmente repartíveis. A concretização de uma política social adequada ganha expressão efectiva com a criação de bairros urbanisticamente controlados para operários. Concebidos no contexto das grandes cidades europeias, estes conjuntos habitacionais garantem algo de verdadeiramente inovador: o acesso dos operários à propriedade urbana. O longo caminho que os filantropos e os movimentos reformistas haviam iniciado em meados do século XIX europeu ganha sedimentação nas primeiras décadas do século XX.

Esta alongada referência parece-nos essencial para perceber o que está em causa quando se fala em habitação social nos nossos dias. Em muitas intervenções as rotinas burocratizadas parecem ter substituido o espírito que dá sentido à iniciativa pública. A discussão dos princípios da intervenção dão lugar a contabilizações variadas que parecem querer responder por esta via àquilo que a lógica de mercado não incorpora. É assim inevitável que em torno deste precioso bem social se tenham vindo a estabelecer clientelas eleitorais, decisivas nos equilíbrios políticos locais, cuja capacidade reivindicativa fica assim empolada. Ora, cremos nós, que o recurso à história social e institucional do problema da habitação permite repensar objectivos, melhor identificar os protagonistas, melhor situar a correlação circunstancial de forças e assim contribuir mais para tomadas de decisão que recorram a uma efectiva prática reflexiva, na qual o papel do sociólogo será seguramente mais relevante. É nesse sentido que queremos avançar o nosso contributo.

\section{Armadilhas Metodológicas na Análise de Fontes Institucionais: o exemplo do programa das casas económicas em Lisboa (1933-1972) ${ }^{7}$}

A pesquisa que realizámos em torno do processo de planeamento e edificação desta medida de política habitacional do Estado Novo (o Programa das Casas Económicas) abriu-nos novas pistas para compreender o sentido da reinvenção morfológica da cidade. Este é, cremos, um exemplo desse recurso à história social e institucional dos problemas sociais contemporâneos. Através dele pudemos avançar na clarificação dos modos de coadunação das Políticas Sociais de Habitação ao contexto da cidade em crescimento.

Indo por este caminho, como desarmadilhar então o vasto conjunto de pré-noções que nos são tão familiares e sintetizadoras das nossas certezas actuais acerca do que é a habitação social e de quem são os seus destinatários? Seguramente será necessário adoptar mecanismos de distanciamento analítico que funcionem como modo de precaução para tais convicções do nosso saber prévio. Só assim se poderá vir a perceber de onde vêm os sentidos hoje dados a noções como a de habitação social. Há que situar historicamente o surgimento daquilo que nos nossos dias se revela indiscutível porque já adquirido quotidianamente. A análise de como se estruturam as políticas sociais para a habitação (e em que circunstâncias) serve o fim de relativizar as certezas hoje correntes. A análise documental pode nesta circunstância, através da reconstituição da história social de um problema social que se apresenta presentemente como relevante, favorecer uma compreensão desreificada de todo o volume de interpretações acumuladas e certificadoras das características que associamos ao objecto analisado.

Essa relativização passa também por um controlo permanente das próprias fontes utilizadas e dos fins a que se destinam ${ }^{8}$. Aí o

\footnotetext{
Esta reflexão assenta na experiência particular de investigação do autor e tem por base a já referida dissertação de Doutoramento acerca da emergência da intervenção pública sistemática no campo da habitação num contexto de crescimento urbano acelerado. A cidade de Lisboa ao longo do século XX é o cenário de uma transformação morfológica evidente que ganha formas edificadas tão diversas e inovadoras como bairros homogéneos de destinação social pré-definida, na época valorizados socialmente e até considerados de certa forma elitistas, e que vão servir de primeiro ensaio para um conjunto de políticas que posteriormente se vão sucedendo. Vistas a partir dos nossos dias, estas iniciativas de combate "às carências habitacionais", que já nos acompanham em Portugal desde os anos 30, estão banalizadas, pondo em causa o valor de excepcionalidade das primeiras iniciativas enquanto mecanismo de intervenção social e urbanística, e têm conduzido a um certo desgosto colectivo face à "cidade social" de hoje que aparece quase invariavelmente associada à exclusão social e à má qualidade habitacional.

8 A combinação de métodos de análise e de técnicas de tratamento é, frequentemente, travada por imposições normativas de um "dever ser sociológico". A atitude de inibição de um exercício pleno do uso de fontes e documentos tidos como "menos próprios" resulta menos de uma necessidade operatória do que de um "senso comum científico" assente num discurso oficial das ciências sociais, cujas implicações práticas são a manualização das formas de lidar com os "problemas da sociedade".
} 
papel do sociólogo vê-se confrontado com a força da ratificação transposta para a análise sociológica das representações correntes do mundo social e pela limitação do exercício crítico daquilo que foi e como foi recolhido. Esta visão institucional é em larga medida homóloga do discurso oficial sobre os problemas oficiais em que os organismos de Estado, habilitados pelas suas competências burocráticas, se especializam e que segundo Bourdieu se sustenta no "pensamento do pensador funcionário" (Bourdieu, 1994:105).

Reside neste ponto a nossa preocupação. Assim, se lidamos essencialmente com dados produzidos oficialmente no âmbito de organismos estatais, como é possível evitar a armadilha, institucionalmente produzida, de uma leitura indiscutível dos dados fornecidos? Como podemos escapar às explicações oficiais dos problemas sociais tidos como relevantes e caminhar para uma interpretação dos processos que lhes estão ligados? Como chegar à compreensão dos interesses em jogo e da actuação dos agentes implicados na resolução dos referidos problemas?

Colocam-se-nos questões de método e de conteúdo. Em primeiro lugar porque as formas tradicionais de gestão dos métodos sociológicos limitam a inventividade de meios (eventualmente) mais fecundos para interpretar fontes habitualmente "secas" e "preparadas" para dar as respostas só institucionalmente interessantes. Em segundo lugar porque as interpretações simplificadoras tentadas pelas instâncias públicas, participantes e implicadas na explicação e na solução dos "problemas sociais", estão imbuídas da necessidade de legitimação das opções tomadas enquanto poderes decisórios.

Se aceitarmos a ideia que Bourdieu apresenta de que nas "nossas sociedades, o Estado contribui de forma determinante na produção e na reprodução dos instrumentos da construção da realidade social enquanto estrutura organizacional e instância reguladora das práticas" (Bourdieu,1994: 125), então o trabalho do investigador é essencialmente o de descodificador, e logo recodificador com intuito explicativo, das interpretações reificadas como factos. Levado a fazer uso das classificações estatalmente produzidas, através da legislação e da estatística, impõe-se ao sociólogo confrontar o dito com o feito, já que são as práticas institucionais que nos permitem confrontar o domínio da racionalidade instituída com o resultado efectivo da actuação programada.

No nosso caso, o teste à aplicação do discurso dos dirigentes estatais ligados à habitação está simplificado graças à possibilidade de observar o resultado prático das suas intenções. Os bairros e os conjuntos residenciais edificados ${ }^{9}$, enquanto objecto da nossa análise, ainda hoje existentes, libertam-nos de formas de controlo metodológico mais elaboradas.

Esta vantagem analítica não impediu, todavia, a necessidade de desenvolvimento de mecanismos de controlo da informação produzida estatalmente. Como afirma Bourdieu, o Estado concentra a informação, trata-a e redistribue-a, operando uma unificação teórica (Bourdieu, 1994:114). Esta operação de totalização, objectivação e codificação (Recenseamentos e Estatísticas, Cartografia e Fiscalidade, Legislação e Controlo dos Comportamentos), a que este autor se refere, tem um significado de homogeneização fundamental: cria sistemas de classificação uniformes, formas de procedimento burocrático e logo desenvolve o já referido tipo de pensamento oficial.

Foi neste emaranhado classificatório, conhecido para quem lida com este tipo de informação e de documentos, que nos encontrámos. Procurámos por isso não separar a utilização de certas aplicações analíticas do quadro teórico em que os conceitos a que recorremos são concebidos e pertinentes. Daí que teoria e metodologia surjam de forma interagente e que tomemos posição, mesmo de entre as várias teorias sociológicas, por aquela que cremos mais fecunda para a explicação dos dilemas que se nos colocam ${ }^{10}$.

Não ignoramos, contudo, no nosso esquema de análise que outros elementos de reflexão, mesmo fora do campo da Sociologia, nos podem ser úteis ${ }^{11}$ : esta reflexão é essencialmente praticada. Dito doutro modo é o próprio pros-

\footnotetext{
9 São 13 os Bairros de Casas Económicas construídos entre 1933 e o final dos anos 50 e 2 os grandes conjuntos habitacionais, um dos anos 40 e outros dos anos 60/70. Todos eles só no concelho de Lisboa e todos eles definidos a partir de legislação criada para o efeito.

10 A noção de campo burocrático de poder desenvolvida nos trabalhos de Pierre Bourdieu e outros, como por exemplo o já referido Christian Topalov, parece-nos particularmente apropriada para a compreensão da complexa emergência e definição de políticas sociais de habitação. Em complemento, a ideia de construção social de populações, desenvolvida por J. C. Chamboredon, entre outros, e cuja génese encontramos em Raymond Ledrut, permite concretizar a aplicação da noção precedente no caso da instalação residencial em contextos de alteração urbana nos quais a componente da intervenção pública é central.

11 Tal posicionamento reenvia-nos para a ideia, sintetizada por J. Madureira Pinto (1994) ao enunciar o segundo princípio de orientação pedagógico-programática de uma disciplina de iniciação às Ciências Sociais, de incentivar a interdisciplinaridade e libertar a imaginação metodológica.
} 
seguimento da investigação que nos incentiva a fazer uso das referências teóricas e metodológicas, as sociológicas e as demais, as quais se vão sucedendo enquanto dissecadoras das várias necessidades do trabalho empírico. Ao longo dos diversos momentos da investigação fomos recorrendo aos meios que pensámos mais fecundos para melhor explicitar a nossa análise.

Tomámos como ponto central da pesquisa a relação que se vai processando entre a capacidade de diagnóstico e programação que os governos instituídos vão desenvolvendo, ao longo do período de vida do Programa das Casas Económicas, 1933-1969/72, o efectivo ordenamento urbano e a correspondente ordenação social das categorias sociais constituídas enquanto objecto de planeamento. E constatamos que se há inegavelmente uma reprodução de velhas lógicas desigualitárias, há também sem dúvida um acréscimo de novas modalidades diferenciadoras que se reflectem quer na reestruturação do espaço físico quer na redefinição da condição dos residentes face à habitação. Ora, é através destas novas configurações espaciais e sociais que passa a nossa linha de inquirição.

A nível dos conteúdos queremos salientar que a tentativa de desarmadilhação passou por tentar ligar duas ordens de questões, aparentemente desfasadas entre si, mas, que são em igual medida decisivas na explicação da ideia da emergência da habitação social na cidade em reinvenção. Ou seja, procurámos, por efeito de articulação das componentes analíticas, contribuir para a compreensão da alteração da estrutura morfológica ${ }^{12}$ da cidade de Lisboa.

A articulação do crescimento demográfico da cidade de Lisboa e das respostas estatais às carências habitacionais na capital portuguesa é aliás inevitável já que perante esse dado reconhecido de um aumento populacional esmagador da cidade ${ }^{13}$ se prevê, no contextos das sociedades com aparelhos de Estado modernos, respostas habitacionais. Então como se explica o desfasamento temporal na resposta estatal a este problema numa época (primeiras décadas do século XX) em que a intervenção pública noutros países europeus era já evidente? ${ }^{14}$
Sabendo de antemão que a tentativa de resolução dos problemas sociais só se faz após estes se terem constituído enquanto tal (e não por reacção aos acontecimentos em contextos internacionais), cremos ser possível encontrar nos tempos do crescimento urbano em Portugal e nos consequentes tempos da intervenção pública directa na habitação os ingredientes para a resolução do enigma deste desajustamento.

Deste modo, o caminho seguido foi o de, num primeiro momento, levantar de forma sistemática os dados necessários que permitissem reconstituir a formação do que hoje se chama a área metropolitana de Lisboa, não esquecendo a sua contextualização a nível nacional, procurando atribuir-lhe a importância particular que a dilatação populacional da maior cidade do país tem na recomposição de espaços e de populações concretos.

O número vale o que permite pensar relacionalmente $^{15}$ e daí a nossa preocupação de uma análise comparativa do crescimento da cidade de Lisboa no seu contexto regional, relacionada com a outra área de maior concentração populacional do país, e em relação a outras cidades da Europa do Sul. O recurso aos dados publicados pelo Instituto Nacional de Estatística para mais de um século permitiu-nos identificar os momentos decisivos do crescimento da cidade e inserir a sua explicação num âmbito mais vasto.

Seguidamente procurámos reconstituir o processo de emergência e de afirmação de uma intervenção sistemática das instâncias públicas no domínio da habitação, eventual antídoto contra a desregulação social. Aqui a diversidade de possibilidades de escolha das vias a tomar obrigou-nos a optar em função das questões que se nos colocavam. Quisémos saber onde, quando e como estas intervenções haviam surgido, de forma a clarificar a fórmula política e ideológica encontrada no domínio governativo para dar resposta a um dos resultados visíveis associados ao crescimento acelerado das cidades: o aumento de uma população desabrigada ou vivendo com "carências habitacionais".

\footnotetext{
12 A noção a que fazemos aqui referência está claramente explicitada em M. Halbwachs no seu trabalho Morphologie Sociale de 1938 e em Tratado de Sociologia (organização de G. Gurvitch), 2 vols., Liv. Martins Fontes, Lisboa, 1977 e remete quer o plano do espaço construído quer para o plano da composição das populações da cidade.

13 Tivemos oportunidade desenvolver esta questão noutro momento. Ver Bibliografia.

14 Encontramos no trabalho de A. Fonseca Ferreira, Por uma Política de Habitação, 1987, a ideia de que "nunca existiu entre nós - antes ou depois do 25 de Abril - uma política de habitação definida de forma explícita e coerente. Têm existido, sim, medidas e programas avulsos, criados e geridos ao sabor das conjunturas políticas e financeiras, sem a adequada preparação prévia nem a garantia dos meios para a respectiva concretização. A execução de qualquer política pressupõe, antes de tudo, a respectiva definição e planificação." (p. 31)

15 Esta ideia que Pierre Bourdieu utiliza para explicitar a necessidade de não opôr teoria e metodologia (1989:23) vem aqui a propósito da necessidade de evitar a utilização descritiva dos dados estatísticos mas antes procurando a sua aplicação explicativa.
} 
Seguimos a direcção através da qual se antevia o fio condutor das iniciativas públicas na habitação. A generalizada referência nos documentos consultados ao Decreto-Lei $n^{\circ}$ 23.052 de 1933, que institui o Programa das Casas Económicas, fundador da intervenção pública directa, permitiu que estabelecessemos o nosso ponto de partida. Estávamos perante a primeira política, ainda que limitada numa perspectiva actual, de intervenção pública sistemática no campo da habitação. Depois dela não se pode falar mais da inexistência de políticas de habitação em Portugal; o que se poderá, isso sim, é considerar a sua limitada possibilidade de resolver o problema social da habitação ou mesmo discordar do sentido das medidas que lhe estão associadas.

Tal linha de investigação obrigou-nos a lidar com um tipo de documentação (legislação e outros documentos institucionais) particularmente assustador para investigadores leigos, na medida em que se encontra presa em lógicas institucionais complexas e organizada segundo critérios legislativos e institucionais próprios. Neste caso concreto, dos programas de intervenção no campo da habitação, os procedimentos institucionais vão sofrendo uma alteração profunda (de 1933 até 1969) à medida que aumenta a importância numérica dos conjuntos edificados e das populações-alvo. Tal situação conduziu a formas diversas de quantificar e classificar pelo que o exercício explicativo se foi revelando progressivamente mais difícil à medida que nos aproximávamos da actualidade. Como salienta P. Bourdieu o "capital jurídico é uma forma objectivada e codificada do capital simbólico que segue a sua própria lógica" (Bourdieu,1994:117) que escapa aos leigos e que se revela um campo determinante na definição do poder arbitrário de impôr soluções aos destinatários legislados.

Também a distância que vai da "norma oficial tal qual é enunciada no direito administrativo e a realidade da prática administrativa", e que Bourdieu bem escalpeliza (Bourdieu, 1994:132-133) nos modos como o enunciado é pervertido nas formas de aplicação aos casos concretos, constituiu um aspecto central na análise da legislação e dos diversos documentos institucionais.
Em termos documentais tivémos de recorrer a toda a legislação que foi sendo produzida ao nível da intervenção pública na habitação, desde 1918 ${ }^{16}$. Tal facto, que resulta da necessidade de confrontar posições ideológicas ${ }^{17}$ e institucionais, permitiu-nos apesar da eventual dispersão da informação recolhida esclarecer os pressupostos e o fio condutor da intervenção pública no campo habitacional ao longo de 40 anos.

A análise discursiva incidiu apenas nos casos consumados de "edificação social", ou seja sempre que se concretizaram fisicamente as iniciativas sobre as quais se produz a informação, e teve o cenário nacional como referência fundamental para compreender a situação de Lisboa.

Em termos temporais não definimos limite a montante, dado que o nosso objectivo era identificar o processo de constituição do campo da habitação social e da edificação de políticas sistemáticas de intervenção, tendo-se estendido o mesmo critério ao processo de crescimento populacional. Já a jusante o desenvolvimento permanente de novas iniciativas, cada vez mais diversificadas e localizadas, obrigou a colocar como momento terminal a extinção do Programa das Casas Económicas que coincide com a remodelação total da política habitacional, entre 1969 e 1972, e que coincide historicamente com a quebra demográfica acentuada da cidade de Lisboa no seu contexto metropolitano.

\section{É Possível Desarmadilhar Metodológica e Conceptualmente os Objectos em Análise?}

Face àquilo que fica atrás exposto, o que podemos concluir acerca da possível desarmadilhação dos objectos em análise? Antes de mais que se trata tão só de uma possibilidade, sempre colocada no plano condicional, na medida em que um primeiro nível de trabalho na elaboração sociológica passa por operarmos com as nossas pré-noções, sejam elas resultantes de trabalhos anteriormente realizados ou de outras ideias recolhidas de origens variadas (leituras, reflexões individuais ou partilhadas). Em qualquer nova circunstância de investigação é fulcral ultrapassar esse primeiro nível de indagação.

\footnotetext{
${ }^{16}$ Consultámos exaustivamente o Boletim do Instituto Nacional do Trabalho e Previdência, através do qual foi possível recolher as informações acerca do Programa das Casas Económicas e dos consequentes programas que passaram pela alçada do Ministério das Corporações; o Boletim do Gabinete Técnico de Habitação da Câmara Municipal de Lisboa, cuja actividade no domínio do alojamento da capital é central a partir de 1959 e o material disponível do Fundo de Fomento da Habitação, criado em 1969 e que constituíu um ponto de viragem no que havia sido feito até aí no campo da habitação social.

17 Parecem-nos interessantes a este propósito as reflexões desenvolvidas por J. Madureira Pinto relativamente à "neutralidade" e "seriedade" na utilização das "técnicas de recolha de informação" enquanto questões epistemológicas prévias na abordagem da questão das ideologias no quadro de problemáticas sociológicas $(1978,9-14)$
} 
Ora, tal processo, de desarmadilhação dos objectos em análise, não pode ser desenvolvido como se de uma rotina se tratasse. Antes devemos pensar que face à construção de um novo objecto de análise sempre se deve prever uma descodificação clara dos pontos de vista dos participantes científicos, dos pontos de vista dos interlocutores institucionais, dos mediadores da informação recolhida, dos portadores de opinião, assim como o controlo metodológico do próprio material recolhido.

Retomando como exemplo a habitação de fins sociais, um primeiro nível de indagação pode quedar-se pela identificação do que seriam comportamentos-tipo dos que pensam, dos que constroem e dos que vivem a habitação social. Assim, em face dos resultados de investigações anteriores ou até de uma representação impressionista do conjunto da realidade observada, podem estabelecer-se novos padrões de caracterização deste mundo social, já devidamente reificados, e que com frequência conduzem à definição de novas verdades acerca do domínio. Ora, não chega. O trabalho sociológico de descodificação é um trabalho de risco realizado no decorrer da própria investigação e exige uma predisposição à exercitação da reflexividade enquanto prática científica que não reproduz de forma livresca as belas ideias da Sociologia mas que delas faz instrumento de interpretação das realidades à mercê dos nossos olhares. A razão de ser e a pertinência do trabalho sociológico começa, do nosso ponto de vista, por aí.

\section{Bibliografia}

BAIGORRI, A.(1995), "Del urbanismo multidisciplinario a la urbanística transdiciplinaria. Una perspectiva sociológica" in Ciudad y Territorio Estudios Territoriales, III (104): 315-328.

BAPTISTA L. (1994), "Dominação demográfica no contexto do século XX português: Lisboa, a capital" in Sociologia-Problemas e Práticas, $n .^{o}$ 15: 53-77.

BAPTISTA L. (1996), Cidade em Reinvenção. Crescimento Urbano e Emergência das Políticas Sociais de Habitação. Lisboa, século vinte, Dissertação de Doutoramento em Sociologia, FCSH-UNL.

BARBiChON,G., DElbos,G., PRADO, P. (1974); L'Entrée dans la ville. Migrants d'origine rurale, migrants d'origine citadine dans deux situations de croissance urbaine, Paris, Centre d'Ethnologie Française.

BOURDIEU, P. (1989), O Poder Simbólico, Lisboa, Difel.

BOURDIEU, P. (1994), Raisons Pratiques. Sur la théorie de l'action, Paris, Éditions du Seuil.

CHAMBOREDON, J.-C., LEMAIRE, M. (1970); "Proximité spatiale et distance sociale. Les grands ensembles et leur peuplement" in Revue Française de Sociologie, vol.XI:3-33.

DE GAULEJAC, V., BONETTI, M., FRAISSE, J. (1995); L'Ingénieur social, Paris, Syros, col. "Alternatives Sociales" (edição original, L'Ingénieur du Développement Social, 1989).

FERREIRA, A. FONSECA (1987), Por uma nova Política de Habitação, Porto, Edições Afrontamento, Colecção "Cidade em Questão".

FERREIRA, V. MATIAS et al. (1997), Lisboa, a Metrópole e o Rio. Centralidade e Requalificação das Frentes de Água, Editorial Bizâncio, Lisboa. 
FERREIRA, V. MATIAS, INDOVINA, F. (organização) (1999); A cidade da EXPO'98. Uma Reconversão na frente Ribeirinha de Lisboa?, Editorial Bizâncio, Lisboa.

GUERRA, I. (1997), "Um olhar sociológico sobre o alojamento" in Sociologia-Problemas e Práticas n. ${ }^{\circ} 24$ : 165-181.

GURVITCH, G.(organização) (1977), Tratado de Sociologia, 2 vols., Liv. Martins Fontes, Lisboa.

LEDRUT, R. (1970), "Les idéologies urbaines" in Economie et Humanisme (194), Julho-Agosto: 58-63.

LEDRUT, R. (1977), L'Espace en Question ou le nouveau monde urbain, Éditions Anthropos, Paris, (em particular o capítulo III:197-141).
PINTO, J. MADUREIRA (1978), Ideologias: inventário crítico dum conceito, Lisboa, Editorial Presença/Gabinete de Investigações Sociais.

PINTO, J. MADUREIRA(1994), Propostas para o ensino das Ciências Sociais, Porto, Edições Afrontamento, Biblioteca das Ciências do Homem, 17.

SOUSA, J. F.(coordenação) (1997), "Cidades, Portos e Frentes de Água" (número temático), Revista Mediterrâneo, Instituto Mediterrânico, FCSH/UNL.

TOPALOV, C. (1990), "De la 'question sociale' aux 'problèmes urbains': les réformateurs el le peuple des métropoles au tournant du XXe siècle" in Revue Internationale des Sciences Sociales, UNESCO, Paris (125), Agosto: 359-376. 